\title{
Endoscopic release of internal snapping hip: a review of literature
}

\author{
Alessio Giai Via ${ }^{1}$ \\ Attilio Basile ${ }^{2}$ \\ Mauricio Wainer ${ }^{1}$ \\ Carlos Musa ${ }^{1}$ \\ Johnny Padulo 3,4 \\ Rodrigo Mardones ${ }^{1}$
}

1 Department of Adult Reconstruction Surgery Hip/Knee and Hip Arthroscopy, Clínica Las Condes, Las Condes, Santiago de Chile, Chile

2 Department of Orthopaedics and Traumatology, Azienda Ospedaliera San Camillo-Forlanini, Rome, Italy

3 University eCampus, Novedrate, Italy

${ }^{4}$ Faculty of Kinesiology, University of Split, Split, Croatia

Corresponding author:

Alessio Giai Via, MD

Department of Adult Reconstruction Surgery

Hip/Knee and Hip Arthroscopy, Clínica Las Condes

La Fontecilla, 441

Las Condes, Santiago de Chile, Chile

E-mail: alessiogiaivia@hotmail.it

\section{Summary}

Background: Internal snapping hip is a common clinical condition, characterized by an audible or palpable snap of the medial compartment of the hip. In most cases it is asymptomatic, while in a few patients, mostly in athletes who participate in activities requiring extremes of hip range of motion, the snap may become painful (internal snapping hip syndrome - ISHS).

Materials and methods: This is a review of current literature, focused on the pathogenesis, diagnosis and treatment of ISHS.

Conclusion: The pathogenesis of ISHS is multifactorial, and it is traditionally believed to be caused by the tendon snapping over the anterior femoral head or the iliopectineal ridge. Most cases of ISHS resolve with conservative treatment, which includes avoidance of aggravating activities, stretching, and NSAIDs. In recalcitrant cases, surgery may be indicated. Better results have been reported with endoscopic iliopsoas tendon release compared with open techniques, which may be related to the treatment of concomitant intra-articular pathologies. Furthermore, endoscopic treatment showed fewer complications, decreased failure rate and postoperative pain. It is important to remember that in most cases, a multiple iliopsoas tendon may exist, and that the incomplete release of the iliopsoas tendon can be a reason for refractory pain and poor results. Then, even if of not clinical relevance at long term follow-up, patients should be told about the inevitable loss of flexion strength after iliopsoas tenotomy.

Level of evidence: II.

KEY WORDS: endoscopy, hip arthroscopy, internal snapping hip, iliopsoas tendon, tendinopathy, tendon release.

\section{Introduction}

Hip arthroscopy has gained considerable popularity in the past decade. The most common indications for hip arthroscopy are intra-articular pathologies, but advances in imaging techniques and arthroscopic procedures allow for the diagnosis and treatment of extra-capsular diseases of the hip. The iliopsoas tendon has gained popularity in the last years for its role as a source of hip pain and its association with intra-articular pathologies. This review is written according to the ethical standards of the journal ${ }^{1}$.

Internal snapping hip or medial coxa saltans is a clinical conditions which was first described by dr. Jones in $1920^{2}$, and it is characterized by an audible or palpable snap of the medial compartment of the hip. It is a common asymptomatic condition which may occur in up to $10 \%$ of the general population ${ }^{3}$, while in a few cases the snap became painful, called Internal Snapping Hip Syndrome (ISHS). In a selected population the incidence of symptomatic medial snapping hip may be higher, in particular in those athletes who require extreme hip motion, as soccer players, weight lifters, and runners ${ }^{4}$. For example, a survey of elite ballet dancers reported that more than $90 \%$ of dancers reported snaps, cracks, clicks of their hip, and in $80 \%$ of cases the symptoms were bilateral, causing pain during hip external rotation and abduction near or beyond $90^{\circ}$. Even if ISHS seems to be more frequent in women than in men, gender is not a statistically significant risk factor ${ }^{6}$. 


\section{Pathogenesis of internal snapping hip}

The origin of ISHS is multifactorial. A complex anatomic relationship exists between the iliopsoas tendon at the musculotendinous junction and the anterior structures of the hip joint. The femoral head, the iliopectineal ridge, the iliopsoas bursa, and the iliofemoral ligament could be involved in the snapping phenomenon. ISHS is traditionally believed to be caused by the iliopsoas tendon snapping over the anterior femoral head or the iliopectineal ridge, which is the rounded elevation on the superior surface of the pelvis where the iliac and pubic bones join. The iliopsoas tendon is located lateral to the iliopectineal eminence when the hip is in full flexion, while during hip extension the tendon moves medially. However, this is not the only pathogenetic mechanism involved. Recent studies showed that the snap may be caused by the movement of the iliacus muscle itself, and not only by the iliopsoas tendon. A dynamic ultrasonographic study showed abnormal movement of the iliacus muscle between the pubic bone and the iliopsoas tendon resulting in snap ${ }^{7}$. Winston et al. observed that the iliopsoas tendon can be embedded within the iliacus muscle belly and produce a snap when returning to its normal position deep to the muscle ${ }^{5}$. Then, other structures may be involved in the development of the snap, as the lesser trochanter and paralabral cyst $^{7}$. Some anatomic variant may also contribute to snapping. Recent investigations focused the attention on the presence of multiple iliopsoas tendon, which could cause snapping by the medial head flipping over the lateral head of the tendon ${ }^{7,8}$. Fabricant et al. found that an excessive femoral anteversion was correlated with poor pre- and postoperative clinical scores $^{9}$.

\section{Clinical examination and diagnosis}

Patients with ISHS typically refer pain and an audible snap in the groin. They often report difficulty to get in and out of the car, standing up from a seated position and doing sports as running, dancing, and all physical activities that require an high hip range of motion ${ }^{6}$. Then, usually the patient is able to tell the examiner when the snap occurs and to reproduce it voluntary. The reproduction of the audible snap is one of the most sensitive clinical test for the diagnose. To reproduce the snap, with the patient supine, the affected leg is moved from flexion, abduction, and external rotation to extension, adduction, and internal rotation. An audible and palpable snap is usually perceptible between 30 and $45^{\circ}$ of hip flexion ${ }^{10}$.

Even if the diagnosis of ISHS is a clinical one, imaging is important to rule out other pathologies.

Antero-posterior X-ray of the pelvis and cross table view of the hip are important to study the anatomy of the hip. Acetabular anterversion, coxa vara and developmental dysplasia may contribute to the snapping of the iliopsoas tendon ${ }^{10}$. Ultrasound is commonly prescribed for the diagnosis. It is useful because dy- namic ultrasound may document the snapping phenomenon as well as pathologic changes of the iliopsoas tendon and of the bursa ${ }^{5}$. However, as ISHS is frequently associated with intra-articular pathologies in a large number of cases, MRI is currently considered superior to ultrasound for decision making by most of the Authors ${ }^{10}$.

\section{Management of internal snapping hip syndrome}

Treatment of ISHS is primary conservative. Nonsurgical treatments are focused on relieving pain and lengthening the tendon through stretching exercises. Lifestyle modification, stretching of the iliopsoas tendon, shock waves, deep massage, myofascial release, neuromuscular reeducation, NSAIDs and steroid injections have been used with good results from 36 to $67 \%$ of cases 6,11 .

When conservative management fails, surgical treatment is indicated. Two different endoscopic techniques for iliopsoas tendon release have been described, the lesser trochanter and the transcapsular release. The endoscopic release of the iliopsoas tendon at the lesser trochanter was described by Byrd et al. ${ }^{3}$ in 2005 . In his study, 9 patients have been treated with good results and without any complications and recurrence. Good clinical results and low recurrence rate have been reported also by other Authors (Table I).

In the trascapsular release, the tendon release is performed across the hip joint through an anterior capsulotomy (Figure 1). The iliopsoas tendon can be released at the level of the labrum or at the femoral neck. Hwang et al. ${ }^{12}$ recently reported good to excellent results in 22/25 patients treated with transcapsular release of iliopsoas tendon, with a mean improvement of the Harris Hip Score (HHS) from 65 to 84 points. Two patients experienced recurrent snap but only one had a revision surgery. No other complication have been reported. A statistical significant improvement in the clinical score was also reported by Ilizaliturri et al. at 2 years follow-up in 14 patients, with only one recurrence of snapping and no complications $^{13}$.

El Bitar et al. ${ }^{14}$ recently proposed an arthroscopic iliopsoas fractional lengthening. In their study, the Authors reviewed retrospectively 55 patients at 2 years follow-up, and they reported good to excellent clinical result in $82 \%$ of cases. However the rate of recurrence of painful snap was somewhat higher than that reported in other studies, as $18 \%$ of patient reported a recurrence of symptoms.

\section{Discussion}

Even if internal snapping hip is a common condition, there is a limited number of articles published in the literature, with all being retrospective studies collected data. Most reports involved relatively small sam- 
A. Giai Via et al.

Table I. Clinical results of endoscopic ISHS treatment.

\begin{tabular}{|c|c|c|c|c|c|c|}
\hline Author & Year & Technique & Patients & $\begin{array}{l}\text { Follow-up } \\
\text { (months) }\end{array}$ & $\begin{array}{l}\text { Recurrence } \\
\text { of symptoms }\end{array}$ & $\begin{array}{l}\text { Score } \\
\text { systems }\end{array}$ \\
\hline Ilizaliturri et al. ${ }^{34}$ & 2005 & $\begin{array}{l}\text { Endoscopic release at } \\
\text { the lesser trochanter }\end{array}$ & 7 & 21 & 0 & WOMAC \\
\hline Flanum et al. ${ }^{35}$ & 2007 & $\begin{array}{l}\text { Endoscopic release at } \\
\text { the lesser trochanter }\end{array}$ & 6 & 12 & 0 & HHS \\
\hline Anderson and Keene ${ }^{18}$ & 2008 & $\begin{array}{l}\text { Endoscopic release at } \\
\text { the lesser trochanter }\end{array}$ & 15 & 9 & 0 & $\begin{array}{l}\text { Byrd's hip } \\
\text { score }\end{array}$ \\
\hline Wettstein et al. ${ }^{36}$ & 2006 & $\begin{array}{l}\text { Endoscopic } \\
\text { transcapsular release }\end{array}$ & 9 & 3 & 0 & Not evaluated \\
\hline Contreras et al. ${ }^{37}$ & 2010 & $\begin{array}{l}\text { Endoscopic } \\
\text { transcapsular release }\end{array}$ & 7 & 24 & 0 & mHHS, VAS \\
\hline Ilizaliturri et al. ${ }^{13}$ & 2014 & $\begin{array}{l}\text { Endoscopic } \\
\text { transcapsular release }\end{array}$ & 14 & 24 & 1 & WOMAC \\
\hline Ilizaliturri et al. ${ }^{13}$ & 2014 & $\begin{array}{l}\text { Endoscopic release at } \\
\text { the lesser trochanter }\end{array}$ & 6 & 24 & 0 & WOMAC \\
\hline Hwang et al. ${ }^{12}$ & 2015 & $\begin{array}{l}\text { Endoscopic } \\
\text { transcapsular release }\end{array}$ & 25 & 24 & 2 & $\begin{array}{l}\text { HHS, HOS- } \\
\text { ADL, HOS-SSS, VAS }\end{array}$ \\
\hline El Bitar et al. ${ }^{14}$ & 2014 & $\begin{array}{l}\text { Fractional iliopsoas } \\
\text { tendon lengthening }\end{array}$ & 55 & 24 & 10 & $\begin{array}{l}\text { NAHS, HOS- } \\
\text { ADL, HOS- } \\
\text { SSS, mHHS, VAS }\end{array}$ \\
\hline
\end{tabular}

VAS: Visual Analogue Scale; HHS: Harris Hip Score; mHHS: modified Harris Hip Score; WOMAC: Western Ontario and McMaster Universities Osteoarthritis Index; NAHS: Non-Arthritic Hip Score; HOS-ADL: Hip Outcome Score-Activity of Daily Living; HOS-SSS Sport-Specific Subscale.

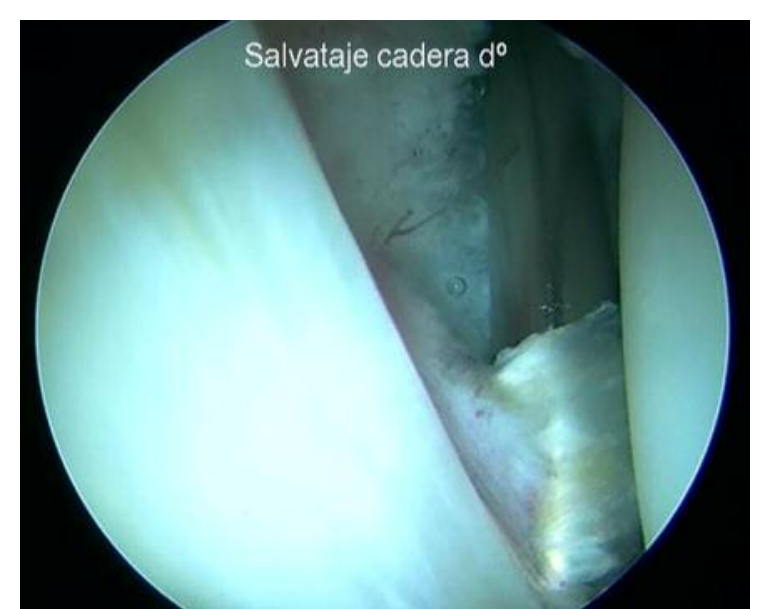

Figure 1. Transcapsular release of the iliopsoas tendon at the level of the acetabular labrum.

ples and short-term follow-up. Then, different evaluation scales have been used to report the outcomes, and this makes comparison of results very difficult. Internal snapping hip is asymptomatic in most of peo- ple, but when the snap becomes painful and conservative management fails, surgical treatment is indicated. Many articles have been reported in the literature about open surgical release or lengthening of the iliopsoas tendon. However the result of open surgery are moderate and an high complication's rate was reported, up to $40 \%$ of cases ${ }^{12,15}$. It probably due to the impossibility to treat intra-articular pathologies. Femoro-acetabular impingement, labral tears and cartilage lesions can be associated with ISHS in more than $50 \%$ of the patients ${ }^{15}$. Sometimes, the iliopsoas tendon itself may cause a labral injury. Domb et al. described an anterior labral injury at the 3 o'clock position directly beneath the iliopsoas tendon, which lies in an extra-articular position immediately beyond the joint capsule ${ }^{16}$ (Figure 2). These patients had no evidence of $\mathrm{FAl}$, bony abnormality, trauma, or any other known cause of labral injury. A complex anatomic relationship exists between the iliopsoas tendon and the anterior surface of the hip joint. The tension on the tendon and the pressure against the femoral head change during the hip range of motion. The pressure of iliopsoas tendon is higher with hip extension, while it decreases during hip flexion, but some anatomical 


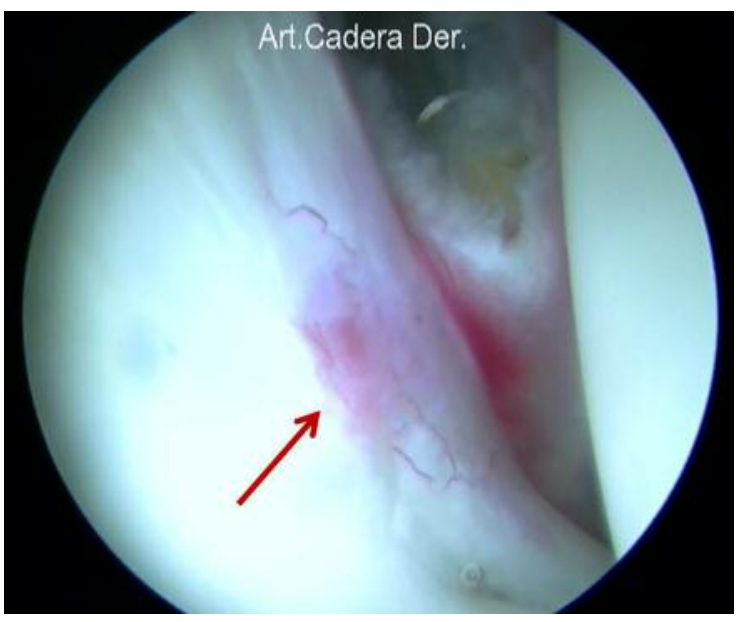

Figure 2. 25-year-old female patient, professional hockey player, affected by ISHS. A labral injury at 3 o'clock position was found.

features are related to an increased pressure. A large femoral head, a varus neck-shaft angle, an high femoral anteversion, a thin but wide tendon at the level of the femoral head, are all conditions associated with higher pressures on the femoral head during hip flexions which may cause a labral injury ${ }^{17}$. For these reasons, Domb et al. proposed the term iliopsoas impingement ${ }^{16}$.

Encouraging results have been reported with endoscopic release of the iliopsoas tendon. Higher success rate, less recurrence, fewer complications, and decreased postoperative pain compared to open surgery have been reported $10,18,19$. Currently, there are more articles available in literature about the iliopsoas tendon release at the lesser trochanter than transcapsular release. One disadvantage of iliopsoas release at the lesser trochanter is that it requires fluoroscopic guide to access the tendon. Then, some Authors reported a greater loss of flexion strength compare to transcapsular release, probably because the muscular portion is preserved when the release is performed at the central compartment ${ }^{13}$. On the other hand, a possible risk of femoral nerve branches injury exists when a transcapsular release is performed, as the nerve runs directly over the iliopsoas muscle ${ }^{20}$. Then, as the medial femoral circumflex artery is close to the psoas tendon, the risk of osteonecrosis of the femoral head also exists ${ }^{21}$. However, these complications have not been reported. Only one comparative study between the two techniques has been published. In this retrospective study by Ilizzaliturri et al. ${ }^{13}$, no significant differences have been found between the two techniques, suggesting that both methods are effective and safe for the treatment of ISHS. But, a cadaveric study showed changes in the anatomy of the iliopsoas tendon according the distance from the lesser trochanter ${ }^{22}$. At the level of the labrum, the muscle-tendineous junction consists of $60 \%$ muscle and $40 \%$ tendon. At the femoral neck it is about a $50-50 \%$, whereas at its insertion on the lesser trochanter, it consists of $40 \%$ muscle and $60 \%$ tendon. So, some Authors suggest that the intracapsular release should be the ideal site for tenotomy because the muscular portion of the iliopsoas muscle is preserved, while releasing the tendon at the lesser trochanter would be equivalent to releasing the entire iliopsoas muscle belly-tendon complex ${ }^{23}$. However these conclusions are based on cadaveric anatomic studies, and we do not know if the level of the tenotomy may produce real differences in term of flexion strength.

Endoscopic release of iliopsoas tendon is not without troubles. Some researchers recently focused the attention on the presence of multiple iliopsoas tendons. In an anatomical cadaveric study of 53 specimens by Philippon et al., two tendons were identified in $64.2 \%$ of cases, three tendons in $7.5 \%$ of cases, while a single tendon was found only in $28.3 \%$ of cases ${ }^{24}$. Crompton et al. found a prevalence of a bifid iliopsoas tendon of $26 \%$ on MR imaging in 87 hips in children $^{25}$. More recently, an incidence of multiple iliopsoas tendons of $18 \%$ during endoscopic transcapsular release have been reported ${ }^{26}$. These studies suggest that, once thought to be a rare anatomic variant, the finding of 2 or multiple iliopsoas tendons is very common, and that it is important to be aware of the possibility that more than 1 tendon may exist. An incomplete release of the iliopsoas tendon should be considered as a differential diagnosis for refractory pain and internal snapping. Therefore, these Authors suggest that if a tendon smaller than $10 \mathrm{~mm}$ of diameter is encountered, an additional tendon should be sought, because it likely represents only one portion of the tendon. The presence of a bifid psoas tendon and an incomplete release may be the cause of recurrence of ISHS and may require a revision surgery. A significant loss of flexion strength is experienced by all patients after surgery. An interesting MRI study recently evaluate the changes of the hip muscles in patients after arthroscopic iliopsoas tenotomy ${ }^{27}$. The Authors found that $85 \%$ of patients showed atrophy of the iliacus muscle, $75 \%$ of them of the psoas muscle, and that the severity of the atrophy was statistically significant greater in the psoas than in the iliacus muscle. According to the grade $28,55 \%$ of patients had a grade 4 atrophy, $10 \%$ a grade 3 and $20 \%$ a grade 2 , and $2 / 20$ patients showed no signs of atrophy at the MRI study. Muscle atrophy was observed also in the omolateral gluteus maximus $(25 \%)$, quadratus femoris (10\%) and vastus lateralis $5 \%$. Surprisingly a high percentage of patients developed an atrophy of the ipsilateral gluteus maximus, probably consequently to the loss of strength of the antagonistic muscles. Another interesting finding was that the atrophy was not associated with a significant decrease in hip function. In fact, there was no significant difference in the modified HHS of the patients with no atrophy, mild to moderate atrophy, and severe iliacus or psoas muscle atrophy at two years follow-up, and the majority of the patient's with grade 4 atrophy showed good clinical outcomes ${ }^{27}$. According to this this study, other Authors reported a significant clinical 
loss of flexion strength after surgery in all patients but they improved in a period lasting from 6 to 10 weeks 26,29 .

A potential risk of hip instability after iliopsoas tenotomy has been reported. Iliopsoas tendon is an important active stabilizer of the hip joint. As the pressure of iliopsoas tendon against the femoral head increases with hip extension, it plays an important role in hip stability together with the anterior capsule-ligaments complex. Some cases of micro-instability, early joint degeneration, subluxation and hip dislocation have been reported after labral repair, acetabular rim trimming and iliopsoas tenotomy ${ }^{30-33}$. However, most of these cases have concomitant factors of instability, like a decreased Center-Edge angle (CE angle), labral hypertrophy and hip dysplasia. Hip dysplasia, excessive acetabular rim trimming, excessive capsulotomy, iliopsoas tenotomy, ligamentum teres resection, ligamentous laxity, and long distraction time resulting in ligament elongation, have been all recognized as potential risk factors for post-operative hip instability. Iliopsoas tenotomy is of course not the only responsible of hip instability, however, many Authors suggest a careful selection of the patient and caution in performing large capsulotomy and excessive acetabular rim trimming in presence of risk factors of instability ${ }^{30,31}$.

\section{Conclusion}

The iliopsoas tendon is a recognized source of extraarticular hip pain. Careful clinical examination and accurate diagnosis is important in patients with ISHS, because the iliopsoas tendon may not be the only responsible of the symptoms. Endoscopic release provides better outcomes, better cosmetic result and less complications than open management. It is important to remind that two or more tendons may exist, and that a partial tendon release may results in recurrence of symptoms. Finally, iliopsoas atrophy is expected in all patients after tenotomy, however it does not seem to be predictive of clinical function. High evidence with long term follow-up are still lacking in literature, in order to define the best treatment for patients affected by ISHS.

\section{References}

1. Padulo J, Oliva F, Frizziero A, Maffulli N. Muscles, Ligaments and Tendons Journal. Basic principles and recommendations in clinical and field science research: 2016 Update. MLTJ. 2016;6(1):1-5.

2. Jones FW. The anatomy of snapping hip. J Bone Joint Surg Am. 1920;2:1-3.

3. Byrd JW. Evaluation and management of the snapping iliopsoas tendon. Tech Orthop. 2005;20:45-51.

4. Wahl CJ, Warren RF, Adler RS, Hannafin JA, Hansen B. Internal coxa saltans (snapping hip) as a result of overtraining: a report of 3 cases in professional athletes with a review of causes and the role of ultrasound in early diagnosis and management. Am J Sports Med. 2004;32:1302-1309.
5. Winston P, Awan R, Cassidy JD, Bleakney RK. Clinical examination and ultrasound of self reported snapping hip syndrome in elite ballet dancers. Am J Sports Med. 2007;35:118-126.

6. Lewis CL. Extra-articular Snapping Hip:A Literature Review. Sports health. 2010;2:186-190.

7. Deslandes M, Guillin R, Cardinal E, Hobden R, Bureau NJ. The snapping iliopsoas tendon: new mechanisms using dynamic sonography. AJR Am J Roentgenol. 2008;190(3):576-581.

8. Tatu L, Parratte B, Vuillier F, Diop M, Monnier G. Descriptive anatomy of the femoral portion of the iliopsoas muscle: anatomical basis of anterior snapping of the hip. Surg Radiol Anat. 2001;23(6):371-374.

9. Fabricant PD, Bedi A, De La Torre K, Kelly BT. Clinical outcomes after arthroscopic psoas lengthening: the effect of femoral version. Arthroscopy. 2012;28(7):965-71.

10. Ilizaliturri V, Camacho-Galindo J. Endoscopic Treatment of Snapping Hips, lliotibial Band, and Iliopsoas Tendon. Sports Med Arthrosc Rev. 2010;18:120-127.

11. El Bitar YF, et al. The American Journal of Sports Medicine 2014.

12. Hwang DS, Jung-Mo Hwang JM, Kim PS, et al. Arthroscopic Treatment of Symptomatic Internal Snapping Hip with Combined Pathologies. Clinics in Orthopedic Surgery. 2015;7:158163.

13. Ilizaliturri VM, Buganza-Tepole M, Olivos-Meza A, Acuna M, Acosta-Rodriguez E. Central Compartment Release Versus Lesser Trochanter Release of the lliopsoas Tendon for the Treatment of Internal Snapping Hip: A Comparative Study. Arthroscopy. 2014;30:790-5.

14. El Bitar YF, Stake CE, Dunne KF, Botser IB, Domb BG. Endoscopic partial tendon release Arthroscopic lliopsoas Fractional Lengthening for Internal Snapping of the Hip Clinical Outcomes With a Minimum 2-Year Follow-up. Am Jour Sports Med. 2014;42:1696-1673.

15. Hoskins JS, Burd TA, Allen WC. Surgical correction of internal coxa saltans: a 20-year consecutive study. Am J Sports Med. 2004.

16. Domb BJ, Shindle MK, McArthur B, Voos JE, Magennis EM, Kelly BT. Iliopsoas impingement: a newly identified cause of labral pathology in the hip. HSS J. 2005;7:145-150.

17. Yoshio M, Murakami G, Sato T, Sato S, Noriyasu S, The function of the psoas major muscle: passive kinetics and morphological studies using donated cadavers. J Orthop Sci. 2002;7:199-207.

18. Anderson SA, Keene JS. Results of arthroscopic iliopsoas tendon release in competitive and recreational athletes. Am J Sports Med. 2008;36:2363-2371.

19. Khan M, Adamich J, Simunovic N, Philippon MJ, Bhandari M, Ayeni OR. Surgical management of internal snapping hip syndrome: a systematic review evaluating open and arthroscopic approaches. Arthroscopy. 2013;29:942-8.

20. Ilizaliturri VM Jr, Byrd JW, Sampson TG, et al. A geographic zone method to describe intra-articular pathology in hip arthroscopy: Cadaveric study and preliminary report. Arthroscopy. 2008:24:534-539.

21. McCormick F, Kleweno CP, Kim YJ, Martin SD. Vascular safe zones in hip arthroscopy. Am J Sports Med. 2011;39Suppl:64S-71S.

22. Alpert JM, Kozanek M, Li G, Kelly BT, Asnis PD. Cross-sectional analysis of the iliopsoas tendon and its relationship to the acetabular labrum: an anatomic study. Am J Sports Med. 2009;37:1594-1598.

23. Blomberg JR, Zellner BS, Keene JS. Cross-sectional analysis of iliopsoas muscle-tendon units at the sites of arthroscopic tenotomies: an anatomic study. Am J Sports Med. 2011;39 Suppl:58S-63S.

24. Philippon MJ, Devitt BM, Campbell KJ, et al. Anatomic Variance of the lliopsoas Tendon. Am J Sports Med. 2014;42:807. 
25. Crompton T, Lloyd C, Kokkinakis M, Norman-Taylor F. The prevalence of bifid iliopsoas tendon on MRI in children. J Child Orthop. 2014;8:333-336

26. Ilizaliturri VM, Suarez-Ahedo C, Acuña M. Internal Snapping Hip Syndrome: Incidence of Multiple-Tendon Existence and Outcome After Endoscopic Transcapsular Release. Arthroscopy. 2015;31:1991-5.

27. Hain KS, Blankenbaker DG, De Smet AA, Keene JS, Munoz del Rio A. MR Appearance and Clinical Significance of Changes in the Hip Muscles and Iliopsoas Tendon After Arthroscopic lliopsoas Tenotomy in Symptomatic Patients. HSSJ. 2013;9:236-241.

28. Khoury E, Cardinal E, Brassard P. Atrophy and fatty infiltration of the supraspinatus muscule: sonography versus MR. Am J Roentgenol. 2008;190:1105-1111.

29. Duck-Soo Hwang, Jung-Mo Hwang, Pil-Sung Kim, et al. Arthroscopic Treatment of Symptomatic Internal Snapping Hip with Combined Pathologies. Clinics in Orthopedic Surgery. 2015;7:158-163.

30. Sansone M, Ahldèn, Jònassn, Sward L, Eriksson T, Karlsson J. Total dislocation of the hip joint after arthroscopy and ileopsoas tenotomy. Knee Surg Sports Traumatol Arthrosc. 2013;21:420-423.
31. Mei-Dan O, McConkey MO, Brick M Catastrophic failure of hip arthroscopy due to iatrogenic instability: can partial division of the ligamentum teres and iliofemoral ligament cause subluxation? Arthroscopy. 2012;28:440-445.

32. Matsuda DK. Acute iatrogenic dislocation following hip impingement arthroscopic surgery. Arthroscopy. 2009;25:400404.

33. Ranawat AS, McClincy M, Sekiya JK. Anterior dislocation of the hip after arthroscopy in a patient with capsular laxity of the hip. A case report. J Bone Joint Surg Am. 2009;91:192-197.

34. Ilizaliturri VM Jr, Villalobos FE, Chaidez PA, et al. Internal snapping hip syndrome: treatment by endoscopic release of the iliopsoas tendon. Arthroscopy. 2005;21:1375-1380.

35. Flanum ME, Keene JS, Blankenbaker DG, et al. Arthroscopic treatment of the painful "internal" snapping hip: results of a new endoscopic technique and imaging protocol. Am J Sports Med. 2007;35:770-779.

36. Wettstein M, Jung J, Dienst M. Arthroscopic psoas tenotomy Arthroscopy. 2006;22:907.e1-907.e4.

37. Contreras ME, Dani WS, Endges WK, De Araujo LC, Berral FJ. Arthroscopic treatment of the snapping iliopsoas tendon through the central compartment of the hip: a pilot study. J Bone Joint Surg Br. 2010;92:777-780. 